\title{
PENERAPAN METODE SUGESTI-IMAJINATIF BERBANTUAN MEDIA GAMBAR UNTUK MENINGKATKAN KEMAMPUAN MENULIS PUISI SISWA KELAS III SD NEGERI SUKASARI I
}

\author{
Lida Aletasari Safitri ${ }^{1}$ \\ Mukhidin² $^{2}$ \\ ${ }^{1}$ Mahasiswa STKIP Subang \\ ${ }^{2}$ Dosen STKIP Subang
}

\begin{abstract}
This study aims to determine the ability to write poetry by using suggestionimaginative methods assisted with image media and without using suggestion-imaginative methods assisted by image media. In addition, this study aims to find out significant differences in the ability to write poetry using the suggestion-imaginative method assisted with image media and without using suggestion-imaginative methods assisted by image media. This research was carried out at SD Negeri Sukasari I, class III semester I $2017 / 2018$ academic year. The method used in this study is Quasi Experiment with the Non Randomize Control Pretest and Posttest Design Group design. With this method, the author examines the treatment effect (treatment) given to the experimental class and compared with the control class in an experiment applying the suggestion-imaginative method assisted by the image media in writing poetry. Sampling using proportional sampling techniques. The sample of this study amounted to 20 students in the experimental class using the suggestion-imaginative method assisted by media images and 19 control class students without using suggestionimaginative methods assisted with image media. The sample was given a poetry writing test instrument to obtain data on variable $X$ and variable $Y$. Data analysis used the " $t$ " test technique, which is a statistical analysis technique to determine the mean of variables $X$ and variable $Y$. Through calculations obtained or degrees of freedom of 37. Value "to "Compared to the value of $t$ table" tt "to test the hypothesis. The comparison results show that the value of 4.36 is greater than the tt value of 2.02 at a significance level of $5 \%$ and 2.71 at a significance level of $1 \%$. Thus the alternative hypothesis ( $\mathrm{Ha}$ ) is accepted, namely there is a significant difference in the application of suggestion-imaginative methods assisted by image media to students' poetry writing skills. The conclusion of this study is the average value of students' ability to write poetry in the experimental class is quite good, which is 6.7. While the average value of the ability to write poetry of the control class students is not good that is equal to 5.2. This proves that the application of suggestion-imaginative methods assisted by image media has an effect on increasing the ability to write poetry of third grade students of $S D$ Negeri Sukasari l.
\end{abstract}

Keywords: Writing ability, Suggestion-Imaginary Method 
ABSTRAK

Penelitian ini bertujuan untuk mengetahui kemampuan menulis puisi dengan menggunakan metode Sugesti-Imajinatif berbantuan media gambar dan tanpa menggunakan metode Sugesti-Imajinatif berbantuan media gambar. Selain itu, penelitian ini bertujuan untuk mengetahui perbedaan yang signifikan tentang kemampuan menulis puisi dengan menggunakan metode Sugesti-Imajinatif berbantuan media gambar dan tanpa menggunakan metode Sugesti-Imajinatif berbantuan media gambar. Penelitian ini dilaksanakan di SD Negeri Sukasari I, kelas III semester I tahun ajaran 2017/2018. Metode yang digunakan dalam penelitian ini adalah Quasi Eksperimen dengan rancangan penelitian Non Randomize Control Group Pretest and Posttest Design. Dengan metode ini, penulis meneliti pengaruh perlakuan (treatment) yang diberikan kepada kelas eksperimen dan dibandingkan dengan kelas kontrol dalam suatu percobaan penerapan metode Sugesti-Imajinatif berbantuan media gambar dalam menulis puisi. Pengambilan sampel dengan menggunakan teknik proportional sampling. Sampel penelitian ini berjumlah 20 siswa kelas eksperimen dengan menggunakan metode Sugesti-Imajinatif berbantuan media gambar dan 19 siswa kelas kontrol tanpa menggunakan metode Sugesti-Imajinatif berbantuan media gambar. Kepada sampel diberikan instrumen tes menulis puisi untuk memperoleh data variabel $X$ dan variabel $Y$. Analisis data menggunakan teknik " $t$ " test, yakni teknik analisis statistik untuk mengetahui mean variabel $X$ dan variabel $Y$. Melalui perhitungan diperoleh atau derajat bebas sebesar 37. Nilai "to" dibandingkan dengan nilai $t$ tabel " $t_{t}$ " untuk menguji hipotesis. Hasil perbandingan menunjukkan bahwa nilai to sebesar 4,36 lebih besar dibandingkan dengan nilai $t_{t}$ sebesar 2,02 pada taraf signifikansi 5\% dan 2,71 pada taraf signifikansi 1\%. Dengan demikian hipotesis alternatif (Ha) diterima, yakni terdapat perbedaan yang signifikan tentang penerapan metode Sugesti-Imajinatif berbantuan media gambar terhadap kemampuan menulis puisi siswa. Kesimpulan dari penelitian ini adalah nilai rata-rata kemampuan menulis puisi siswa kelas eksperimen adalah cukup baik yaitu sebesar 6,7. Sedangkan nilai rata-rata kemampuan menulis puisi siswa kelas kontrol kurang baik yaitu sebesar 5,2. Hal ini membuktikan bahwa penerapan metode Sugesti-Imajinatif berbantuan media gambar berpengaruh terhadap peningkatan kemampuan menulis puisi siswa kelas III SD Negeri Sukasari I.

Kata kunci :Kemampuan menulis, Metode Sugesti-Imajinatif

\section{A. Pendahuluan}

Pembelajaran

Indonesia difokuskan pada

keterampilan berbahasa yang

menyangkut pada empat kemampuan dasar, yakni kemampuan menyimak, berbicara, membaca, dan menulis. Mengajarkan kemampuan menulis kepada siswa tidak berarti ingin 
menjadikan siswa seorang peneliti, tetapi setidaknya dengan kemampuan menulis yang baik, siswa dapat berhasil dalam pendidikan. Keterampilan menulis sangat diperlukan untuk menuliskan jawaban ujian-ujian yang berbentuk esai, mengungkapkan gagasangagasan yang lahir agar dapat dibaca orang lain.

\section{Pembelajaran}

Bahasa

Indonesia diarahkan untuk dapat meningkatkan kemampuan siswa dalam berkomunikasi dengan baik dan benar. Komunikasi dilakukan baik secara lisan maupun tulisan, serta menumbuhkan apresiasi terhadap hasil karya kesastraan. Pembelajaran sastra di Sekolah Dasar dalam pelajaran Bahasa Indonesia bertujuan untuk menumbuhkan keterampilan dan ketertarikan siswa terhadap suatu karya sastra. Namun pada kenyataannya masih banyak siswa yang tidak menyukai menulis karena tidak mengetahui untuk apa dia menulis, merasa tidak berbakat dalam menulis, dan tidak tahu bagaimana harus menulis. Sedangkan banyak sekali manfaat dari menulis, diantaranya dalam peningkatan kecerdasan, pengembangan daya imajinatif, inisiatif dan kreativitas, penumbuhan keberanian dan pendorong kemauan dan kemampuan dalam mengumpulkan informasi. Hal tersebut menjadi masalah dalam kegiatan pembelajaran sastra di Sekolah Dasar.

Kemampuan

menulis merupakan salah satu kemampuan berbahasa yang sangat penting untuk dikuasai oleh siswa. Keterampilam menulis merupakan salah satu dari empat komponen keterampilan berbahasa yang mempunyai peranan penting di dalam kehidupan manusia sehingga membutuhkan perhatian yang sungguh-sungguh sejak Pendidikan Dasar. Menulis merupakan kegiatan berbahasa yang cukup kompleks karena pada saat menulis terlibat beberapa unsur yang diterapkan sekaligus. Menulis tidak hanya digunakan untuk mengekspresikan pikiran atau perasaan kepada orang lain, melainkan juga merupakan pengungkapan ide 
atau gagasan, pengetahuan, ilmu dan pengalaman hidup seseorang dalam bahasa tulisan.

Menulis menuntut beberapa kemampuan sekaligus. Di samping harus memiliki pengetahuan tentang apa yang akan ditulis, juga harus mengetahui bagaimana cara menuliskannya. Pertama, menyangkut isi dari tulisan, kedua menyangkut aspek kebahasaan dan teknik penelitian. Dengan demikian, menulis dapat dikatakan sebagai keterampilan yang lebih sulit dibandingkan dengan keterampilan bahasa lainnya.

Tujuan menulis adalah agar tulisan yang dibuat dapat dibaca dan dipahami oleh orang lain yang mempunyai kesamaan pengertian terhadap bahasa yang dipergunakan.Untuk terampil menulis diperlukan latihan dan praktik yang terus-menerus dan teratur. Fungsi menulis ialah sebagai alat komunikasi tidak langsung. Menulis mendorong kita untuk berpikir kritis dan sistematis.Sebelum menulis kita harus merencanakan topik yang akan dibahas dalam tulisan, tujuan yang hendak disampaikan, dan pembahasan yang akan diuraikan. Semua itu dilakukan karena menulis merupakan proses berpikir.

Mengingat pentingnya pengajaran apresiasi dan ekspresi sastra bagi siswa di dalam Kurikulum $2006 \quad$ Standar Kompetensi Mata Pelajaran Bahasa Indonesia untuk SD kelas III terdapat deskripsi standar kompetensi dan kompetensi dasar yang berkenaan dengan apresiasi dan ekspresi sastra. Salah satunya adalah menulis puisi anak berdasarkan gambar.

Menulis puisi merupakan suatu keterampilan sastra yang harus dicapai oleh siswa. Siswa akan memperoleh banyak manfaat dari kegiatan menulis puisi. Beberapa manfaatnya adalah siswa dapat mengekspresikan pikirannya melalui bahasa yang indah dalam puisi, siswa dapat menjadikan puisi sebagai media untuk menuangkan segala perasaannya. Pembelajaran menulis puisi bukan suatu pekerjaan yang mudah jika kita menginginkan hasil yang baik. namun bukan berarti kemampuan 
menulis itu hanya dimiliki oleh orang-orang yang mempunyai bakat tertentu. Kemampuan menulis khususnya kemampuan menulis puisi dapat diikuti oleh setiap siswa asalkan mau belajar dan berlatih dengan sungguhsungguh.

\section{B. Landasan Teori}

\section{Metode Pembelajaran}

Metode pembelajaran menurut Sobry (2014:34) adalah cara-cara menyajikan materi pelajaran yang dilakukan oleh pendidik agar terjadi proses belajar pada diri peserta didik dall.am upaya mencapai tujuan sedangkan menurut Mukhidin (2017) adalah cara mengajar yang dilakukan guru di dalam kelas. Dalam dunia pendidikan metode sangat dibutuhkan, terutama dalam proses pembelajaran di dalam kelas. Sebagai seorang guru harus terampil dalam memilih metode pembelajaran yang tepat dalam materi yang akan diajarkan dan situasi serta kondisi siswa dalam proses pembelajaran.

\section{Metode Sugesti-Imajinatif}

Metode

sugesti

(Sugestopedia) dikembangkan oleh Lozanovo. la adalah seoramg pendidik dan psikoterapis dari Bulgeria. Metode ini diyakini dapat membantu

pembelajar berkonsentrasi dan tanpa disadari pembelajar akan menyimpan berbagai aturan kebahasaan dan sejumlah kosa kata yang pernah diajarkan. (Wassid dan Sunendar, 2008:65)

Metode sugesti diasumsikan bahwa relaksasi merupakan teknik yang tepat untuk digunakan. Sesuatu yang nyaman sangat dibutuhkan dalam penerapan metode ini, untuk menumbuhkan sugesti dalam suatu pembelajaran, dekorasi ruangan kelas yang menarik, dan juga tempat duduk yang menyenangkan. Metode ini menekankan sugesti kepada siswa agar memiliki rasa percaya diri.

Metode imajinatif digagas oleh Kieran Egan, dia adalah seorang Profesor pendidikan pada Simon Fraser Univercitydi Vancouver. Menurut Egan (2009:X) melibatkan imajinasi siswa merupakan hal penting untuk pembelajaran yang sukses. 
Dalam proses pembelajarannya, menulis imajinatif siswa diajarkan menguasai kompetensi menulis secara bebas sesuai imajinasinya. Siswa diberi kebebasan untuk menuangkan ide, pendapat dan imajinasinya ke dalam bentuk tulisan.

Metode Sugesti-Imajinatif adalah metode pembelajaran dengan cara memberikan sugesti menggunakan media lagu, media gambar, atau media film untuk membangkitkan imajinasi siswa. Media yang penulis gunakan dalam penelitian ini adalah media gambar. Dalam proses pembelajaran, media gambar digunakan sebagai pencipta sugestif, stimulus sekaligus menjadi jembatan yang digunakan siswa untuk menciptakan gambaran kejadian berdasarkan gambar. Selain itu media gambar juga dapat merangsang keterlibatan emosional, perhatian, motivasi dan ketekunan siswa dalam pembelajaran menulis.

\section{Metode Penelitian}

Penelitian ini dilakukan dengan menggunakan metode quasi eksperimen. Metode quasi eksperimen yaitu metode yang tidak memungkinkan peneliti melakukan pengontrolan penuh terhadap semua variabel yang relevan. Pengontrolannya hanya dilakukan terhadap satu variabel saja, yaitu variabel yang paling dominan. Penelitian ini dilaksanakan di SD Negeri Sukasari I. Penetapan lokasi penelitian berdasarkan pada beberapa pertimbangan, yaitu jarak yang dekat dan efisien dari segi waktu, dana serta tenaga. Di lokasi tersebut, penulis akan mengumpulkan data dari siswa kelas III sebagai sampel penelitian melalui kegiatan pembelajaran. Subjek penelitian ini adalah siswa kelas III A dan III B SD Negeri Sukasari I. Kelas III A berjumlah 20 siswa dan kelas III B berjumlah 19 siswa.

Sumber data yang diperoleh dalam penelitian ini adalah berasal dari sampel yang diambil berdasarkan padabesar kecilnya sub populasi. (Proportional Sampling). Penelitian ini dilakukan pada dua kelas, yakni kelas eksperimen yang diberikan perlakuan dengan menggunakan 
Didaktik : Jurnal Pendidikan Guru Sekolah Dasar, ISSN : 24775673

Sekolah Tinggi Keguruan dan IImu Pendidikan Subang

Volume IV Nomor 1, Juli 2018

metode Sugesti-Imajinatif

berbantuan media gambar dan

kelas kontrol yang tidak diberikan

perlakuan. Kelas eksperimen adalah kelas yang diberikan perlakuan yaitu kelas III A dan kelas kontrol adalah kelas yang tidak diberikan perlakuan yaitu kelas III B. Pada kelas III A sebanyak 20 siswa, sedangkan pada kelas III B sebanyak 19 siswa. Data yang digunakan berupa skor yang diperoleh dari hasil tes kemampuan menulis puisi.

Soal test tulis yang digunakan penulis adalah test kemampuan menulis puisi. Alat test ini digunakan untuk mengumpulkan data berupa puisi yang ditulis oleh subjek penelitian dalam kaitan dengan percobaan penerapan metode Sugesti-Imajinatif berbantuan media gambar.

D. Hasil Penelitian dan Pembahasan

\section{Deskripsi Data dan Analisis Data}

Melalui kegiatan pengumpulan data dengan menggunakan instrumen tes menulis puisi yang diberikan kepada sampel yang berjumlah 39 siswa kelas III A dan III B SDN Sukasari I, diperoleh data mentah berupa puisi dari 39 siswa tersebut. Berdasarkan desain penelitian yang digunakan, sampel sebanyak 39 siswa tersebut dipilih menjadi subjek kelas eksperimen (KE) sebanyak 20 siswa dan subjek kelas kontrol (KK) sebanyak 19 siswa. Dengan demikian, data mentah berupa puisi tersebut berjumlah 20 puisi dari kelas eksperimen, dan 19 puisi dari kelas kontrol.

Data mentah yang berupa puisi itu dinilai atau dikoreksi, sehingga diperoleh skor kemampuan menulis puisi siswa kelas eksperimen (Kelas $X$ ) dan kelas kontrol (Kelas Y). Penilaian puisi dilakukan dengan menggunakan pedoman penilaian puisi yang memuat 10 aspek penilaian yang memiliki skala nilai 1-5. Yaitu judul, rasa, nada, diksi, imaji, amanat, rima, irama, gaya bahasa dan kata konkret. 
Tabel 1. Skor Puisi Kelas Eksperimen (Kemampuan Menulis Puisi dengan Metode Sugesti-Imajinatif Berbantuan Media Gambar / Kelas X)

\begin{tabular}{|c|c|c|c|c|c|c|c|c|c|c|c|}
\hline \multirow{2}{*}{$\begin{array}{c}\text { No } \\
\text { Subjek }\end{array}$} & \multicolumn{10}{|c|}{ Aspek Penilaian Nomor } & \multirow{2}{*}{$\begin{array}{l}\text { Jumlah } \\
\text { Skor }\end{array}$} \\
\hline & 1 & 2 & 3 & 4 & 5 & 6 & 7 & 8 & 9 & 10 & \\
\hline $\mathrm{X} 1$ & 4 & 3 & 4 & 3 & 3 & 4 & 4 & 4 & 3 & 3 & 35 \\
\hline $\mathrm{X} 2$ & 4 & 3 & 4 & 4 & 3 & 4 & 3 & 3 & 4 & 3 & 35 \\
\hline $\mathrm{X} 3$ & 5 & 4 & 4 & 4 & 4 & 4 & 3 & 4 & 4 & 4 & 40 \\
\hline $\mathrm{X} 4$ & 4 & 4 & 4 & 4 & 4 & 4 & 4 & 4 & 4 & 4 & 40 \\
\hline$\times 5$ & 3 & 3 & 3 & 3 & 3 & 4 & 4 & 4 & 4 & 4 & 35 \\
\hline$x_{6}$ & 2 & 2 & 3 & 2 & 3 & 3 & 3 & 3 & 2 & 2 & 25 \\
\hline $\mathrm{X} 7$ & 3 & 3 & 3 & 3 & 3 & 3 & 3 & 3 & 3 & 3 & 30 \\
\hline$X 8$ & 4 & 4 & 3 & 3 & 3 & 4 & 3 & 4 & 3 & 4 & 35 \\
\hline$X 9$ & 5 & 3 & 3 & 3 & 3 & 3 & 2 & 2 & 3 & 3 & 30 \\
\hline $\mathrm{X} 10$ & 4 & 2 & 2 & 3 & 3 & 4 & 3 & 3 & 3 & 3 & 30 \\
\hline $\mathrm{X} 11$ & 4 & 2 & 2 & 3 & 2 & 2 & 2 & 2 & 3 & 3 & 25 \\
\hline $\mathrm{X} 12$ & 3 & 3 & 2 & 3 & 2 & 2 & 2 & 3 & 3 & 2 & 25 \\
\hline $\mathrm{X} 13$ & 4 & 4 & 4 & 4 & 4 & 4 & 4 & 4 & 4 & 4 & 40 \\
\hline $\mathrm{X} 14$ & 5 & 5 & 4 & 4 & 5 & 4 & 5 & 4 & 5 & 4 & 45 \\
\hline $\mathrm{X} 15$ & 4 & 3 & 4 & 3 & 4 & 3 & 3 & 3 & 4 & 4 & 35 \\
\hline $\mathrm{X} 16$ & 4 & 3 & 3 & 3 & 3 & 3 & 3 & 3 & 3 & 2 & 30 \\
\hline $\mathrm{X} 17$ & 4 & 4 & 3 & 5 & 4 & 3 & 3 & 3 & 3 & 3 & 35 \\
\hline $\mathrm{X} 18$ & 4 & 3 & 3 & 2 & 3 & 3 & 3 & 3 & 3 & 3 & 30 \\
\hline X19 & 4 & 4 & 4 & 4 & 3 & 3 & 3 & 4 & 3 & 3 & 35 \\
\hline$\times 20$ & 4 & 3 & 2 & 3 & 3 & 3 & 3 & 3 & 3 & 3 & 30 \\
\hline
\end{tabular}

Tabel 2. Skor Puisi Kelas Kontrol (Kemampuan Menulis Puisi dengan Metode Sugesti-Imajinatif Berbantuan Media Gambar / Kelas Y)

\begin{tabular}{|c|c|c|c|c|c|c|c|c|c|c|c|}
\hline $\begin{array}{c}\text { No } \\
\text { Subjek }\end{array}$ & \multicolumn{10}{|c|}{ Aspek Penilaian Nomor } & Jumlah \\
Skor
\end{tabular}

Skor puisi di atas diubah menjadi nilai berstandar 1-10. Perubahan ini dilakukan untuk mempermudah pengolahan data secara statistik untuk pengujian hipotesis.

Untuk menempuh pengubahan skor menjadi nilai berstandar 1-10. Untuk menempuh pengubahan skor menjadi nilai berstandar 1-10, maka digunakan rumus sebagai berikut.

$$
\mathrm{N}=\frac{S k}{S i} \times 10
$$

Keterangan :

$$
\begin{array}{ll}
\mathrm{N} & =\text { Nilai } \\
\mathrm{Sk} & =\text { Skor Terendah } \\
\mathrm{Si} & =\text { Skor Ideal }
\end{array}
$$

Berdasarkan rumus konversi tersebut, maka nilai kemampuan menulis puisi siswa kelas eksperimen (nilai kelas $\mathrm{X}$ ) dan nilai kemampuan menulis puisi siswa kelas control (nilai kelas Y) dapat disajikan. 
Tabel 3. Nilai Kemampuan Menulis Puisi Kelas Eksperimen dan Kelas Kontrol

\begin{tabular}{|c|c|c|}
\hline \multirow{2}{*}{$\begin{array}{c}\text { Nomor } \\
\text { Subjek }\end{array}$} & \multicolumn{2}{|c|}{ Nilai Puisi } \\
\cline { 2 - 3 } & $\begin{array}{c}\text { Kelas X (Kelas } \\
\text { Eksperimen }\end{array}$ & $\begin{array}{c}\text { Kelas Y (Kelas } \\
\text { Kontrol) }\end{array}$ \\
\hline 1 & 7 & 4 \\
\hline 2 & 7 & 5 \\
\hline 3 & 8 & 7 \\
\hline 4 & 8 & 6 \\
\hline 5 & 7 & 4 \\
\hline 6 & 5 & 5 \\
\hline 7 & 6 & 4 \\
\hline 8 & 7 & 4 \\
\hline 9 & 6 & 6 \\
\hline 10 & 6 & 4 \\
\hline 11 & 5 & 5 \\
\hline 12 & 5 & 4 \\
\hline 13 & 8 & 5 \\
\hline 14 & 9 & 6 \\
\hline 15 & 7 & 5 \\
\hline 16 & 6 & 7 \\
\hline 17 & 7 & 5 \\
\hline 18 & 6 & 7 \\
\hline 19 & 7 & 5 \\
\hline 20 & 6 & \\
\hline & & \\
\hline
\end{tabular}

Batas

keberhasilan

kemampuan menulis puisi siswa secara individual dan klasikal ditentukan untuk mengetahui pencapaian tingkat keberhasilan atau kemampuan siswa dalam menulis puisi. Dalam hal ini, batas nilai keberhasilan individual adalah 6. Dengan perkataan lain, siswa dianggap mampu menulis puisi jika memperoleh nilai 6 atau di atas nilai 6, dan siswa dianggap tidak mampu menulis puisi jika mendapatkan nilai dibawah 6 . Sementara itu, batas keberhasilan klasikal sebesar $59 \%$ dari keseluruhan siswa memperoleh nilai 6 ke atas.

Berdasarkan data nilai tersebut, dapat diketahui bahwa siswa yang mampu menulis puisi pada kelas eksperimen berjumlah 17 siswa (85\%) atau melebihi batas keberhasilan klasikal dan yang tidak mampu menulis puisi berjumlah 3 siswa atau sebesar $15 \%$. Sebaliknya, siswa yang mampu menulis puisi pada kelas kontrol berjumlah 6 siswa (32\%) atau tidak mencapai batas keberhasilan klasikal dan siswa yang tidak mampu menulis puisi berjumlah 13 siswa atau sebesar $68 \%$.

Distribusi nilai di atas menunjukkan adanya perbedaan kemampuan siswa dalam penelitian menulis puisi. Secara umum, nilai kelas eksperimen lebih baik daripada nilai kelas control. Dengan perkataan lain, kememampuan siswa dalam menulis puisi dengan menggunakan metose SugestiImajinatif berbantuan media gambar lebih baik dibandingkan dengan siswa yang menulis puisi tanpa menggunakan metode 
Sugesti-Imajinatif berbantuan

media gambar. Dapat dikatakan, prestasi belajar siswa kelas eksperimen dipengaruhi oleh penerapan metode SugestiImajinatif berbantuan media gambar dalam menulis puisi.

\section{Analisis Data}

Untuk kepentingan pengujian hipotesis, akan dilakukan analisi data dengan menggunakan parameter statistic. Analisis data diarahkan pada kegiatan pengolahan data untuk memperoleh nilai hitung atau perbedaan rata-rata nilai kelas $X$ dan kelas $Y$. teknik analisis yang digunakan adalah teknik Tes " $t$ ". Dengan menggunakan teknik analisis data tersebut, akan dicari nilai hitung atau nilai to (perbedaan dua mean).

Nilai hitung atau nilai to yang diperoleh akan dibandingkan dengan harga kritik $t$ atau $t$ Tabel ( $\left.\mathrm{t}_{\mathrm{t}}\right)$ dengan menggunakan besaran derajat bebas $(\mathrm{db})$ tertentu. Untuk memperoleh nilai to (perbedaan dua mean), digunakan rumus berikut :

$$
t_{0}=\frac{M 1-M 2}{S E M 1-S E M 2}
$$

(Sudijono, 1992:297)

Keterangan :

to = Perbedaan dua mean

$\mathrm{M}_{1}=$ Mean kelas $\mathrm{X}$

$M_{2}=$ Mean kelas $Y$

$\mathrm{SEM}_{1}$ - $\mathrm{SEM}_{2}$ = Standar error perbedaan dua mean.

Untuk memperoleh Mean kelas $X\left(M_{1}\right)$, Standar Deviasi kelas $\mathrm{X}\left(\mathrm{SD}_{1}\right)$, dan Standar Error kelas $X\left(S_{1}\right)$, serta memperoleh Mean kelas $Y \quad\left(M_{2}\right)$, Standar Deviasi kelas $\mathrm{Y}\left(\mathrm{SD}_{2}\right)$, dan Standar Error kelas $\mathrm{Y}\left(\mathrm{SE}_{2}\right)$, digunakan rumus sebagai berikut :

$$
\begin{aligned}
& M_{1}=\frac{\sum f x}{N_{1}} \text { atau } M_{2}=\frac{\sum f y}{N_{2}} \\
& S D_{1}=1 \sqrt{ }\left(\sqrt{\left.N_{1}\right)\left(\sum f x^{2}\right)-\left(\sum f x\right)^{2}} \quad\right. \text { atau } \\
& \overline{N_{1}} \\
& S D_{1}=\frac{1 \sqrt{ }\left(N_{2}\right)\left(\Sigma f y^{2}\right)-(\Sigma f y)^{2}}{N_{2}}
\end{aligned}
$$

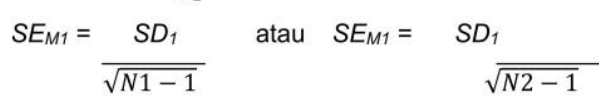

(Sudijono, 1992:152)

Berikut ini adalah rekapitulasi mean $\left(M_{1}\right.$ dan $\left.M_{2}\right)$, standar deviasi $\left(\mathrm{SD}_{1}\right.$ dan $\left.\mathrm{SD}_{2}\right)$, dan standar error $\left(\mathrm{SE}_{1}\right.$ dan $\left.\mathrm{SE}_{2}\right)$ dari kelas $\mathrm{X}$ dan kelas $Y$. 
Tabel 4. Rekapitulasi Mean $\left(\mathrm{M}_{1}\right.$ dan $\mathrm{M}_{2}$ ), Standar Deviasi $\left(\mathrm{SD}_{1}\right.$ dan $\left.\mathrm{SD}_{2}\right)$, dan Standar Error $\left(\mathrm{SE}_{1}\right.$ dan $\left.\mathrm{SE}_{2}\right)$ dari kelas $X$ dan kelas $Y$

\begin{tabular}{|c|c|c|}
\hline Kelas X & Rekapitulasi & $\begin{array}{c}\text { Kelas } \\
\mathbf{Y}\end{array}$ \\
\hline $\mathbf{6 , 7}$ & Mean (M) & $\mathbf{5 , 2}$ \\
\hline $\mathbf{1 , 0 6 1}$ & $\begin{array}{c}\text { Standar } \\
\text { Deviasi (SD) }\end{array}$ & $\mathbf{1 , 0 3 9}$ \\
\hline $\mathbf{0 , 2 4 3}$ & $\begin{array}{c}\text { Standar Error } \\
\text { (SE) }\end{array}$ & $\mathbf{0 , 2 4 4}$ \\
\hline
\end{tabular}

Mencari standar error perbedaan mean kelas $X$ dan mean kelas $Y$ atau $\mathrm{SEM}_{1}-\mathrm{SEM}_{2}$. Untuk memperoleh nilai standar error dari perbedaan mean kelas $X$ dan mean kelas $Y$, digunakan rumus berikut.

$$
S E_{M 1}-S E_{M 2}=\sqrt{S_{M 1}^{2}+S E_{M 2}^{2}}
$$

(Sudijono, 1992:308)

Dengan menggunakan rumus di atas, nilai standar error perbedaan mean kelas $X$ dan mean kelas $\mathrm{Y}\left(\mathrm{SE}_{\mathrm{M} 1}\right.$ - $\left.\mathrm{SE}_{\mathrm{M} 2}\right)$ adalah sebagai berikut.

$$
\begin{aligned}
& S E_{M 1}-S_{M 2}=\sqrt{S_{M} E^{2}+\mathrm{SE}_{M 2} 2} \\
& \left.S E_{M 1}-S_{M 2}=\sqrt{(0,243)^{2}+(0,244}\right)^{2} \\
& S E_{M 1}-S E_{M 2}=\sqrt{0,059049+0,059536} \\
& S E_{M 1}-S_{M 2}=\sqrt{0,118585} \\
& S E_{M 1}-S_{M 2}=\mathbf{0 , 3 4 4}
\end{aligned}
$$

1) Mencari nilai hitung to atau perbedaan mean kelas $\mathrm{X}$ dan mean kelas $Y$ dengan menggunakan rumus berikut.

$$
t_{0}=\frac{M 1-M 2}{S E M 1-S E M 2}
$$

(Sudijono, 1992:297)

Dengan telah diketahuinya mean kelas $X\left(M_{1}\right)$, mean kelas $Y$ $\left(\mathrm{M}_{2}\right)$, dan standar error perbedaan mean kelas $X$ dan mean kelas $Y$ $\left(S_{M 1}-S_{M 2}\right)$ maka nilai to adalah 4,36 sebagai hasil perhitungan sebagai berikut.

$$
\begin{aligned}
t_{o} & =\frac{M 1-M 2}{S E M 1-S E M 2} \\
t_{o} & =\frac{6,7-5,2}{0,344} \\
t_{0} & =\frac{1,5}{0,344} \\
t_{0} & =4,36
\end{aligned}
$$

\section{Pengujian Hipotesis}

Dalam menguji hipotesis penelitian, dilakukan beberapa tahap, yaitu menyusun kembali hipotesis penelitian, menetapkan 
taraf signifikansi dengan pengujian

dua pihak, menentukan kriteria pengujian hipotesis, melakukan interpretasi nilai "to" dengan berkonsultasi pada Tabel nilai " $\mathrm{t}$ " atau nilai $t_{t}$, tt untuk berbagai $d f$, dan menarik ksimpulan.

Dalam penelitian ini hipotesis yang diuji terdiri dari dua rumusan, yaitu hipotesis alternatif/kerja $(\mathrm{Ha})$ dan hipotesis nihil (Ho). Hipotesis alternatif (Ha) berbunyi : "Terdapat perbedaanyang signifikan tentang penerapan metode SugestiImajinatif berbantuan gambar terhadap kemampuan menulis puisi pada siswa kelas III SDN Sukasari I". Sementara itu, hipotesis nihil (Ho) berbunyi : "Tidak terdapat perbedaanyang signifikan tentang penerapan metode Sugesti-Imajinatif berbantuan gambar terhadap kemampuan menulis puisi pada siswa kelas III SDN Sukasari”.

Taraf signifikansi yang digunakan dalam pengujian hipotesis adalah taraf signifikansi (kebermaknaan) 1\% atau taraf reliability (kepercayaan) 99\% dan taraf signifikansi (kebermaknaan) $5 \%$ atau taraf reliability (kepercayaan) 95\%. Nilai to yang diperoleh melalui perhitungan akan dibandingkan dengan besarnya nilai $t$ tabel atau harga kritik " $t$ " $\left(t_{t}\right)$ yang terdapat pada Tabel Nilai "t". Berdasarkan taraf signifkasi tersebut, terlebih dahulu menetapkan derajat kebebasan (db). Rumus untuk menentukan derajat kebebasan (db) atau degrees of freedom (df) yang digunakan adalah :

df atau $d b=\left(N_{1}+N_{2}\right)-2$

(Sudijono, 1992:299) 
Dengan menggunakan rumus tersebut, maka df yang diketahui adalah 37 (20+19-2). Pada Tabel nilai "t" diketahui harga kritik "t" pada taraf signifikansi $5 \%$ atau taraf kepercayaan (5\%) dengan df 37 bernilai 2,02. Adapun harga kritik "t" pada taraf signifikansi 1\% atau taraf kepercayaan 95\% dengan df 37 bernilai 2,71. Dengan demikian, nilai to lebih besar daripada tt, yaitu :

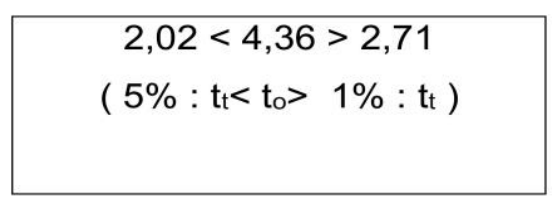

Kriteria pengujian hipotesis adalah jika pada taraf signifikansi $1 \%$ dan $5 \%$ nilai to lebih besar dari nilai $\mathrm{t}$, maka Ha diterima dan Ho ditolak. Sebaliknya, jika to lebih kecil daripada $t$, maka Ha ditolak dan Ho diterima. Karena nilai to lebih besar dari nilai $t_{t}$, maka hipotesis alternatif/ kerja (Ha) yang menyatakan

"Terdapat perbedaanyang signifikan tentang penerapan metode SugestiImajinatif berbantuan gambar terhadap kemampuan menulis puisi pada siswa kelas III SDN Sukasari I", diterima. Sebaliknya, hipotesis nihil (Ho) yang menyatakan "Tidak terdapat perbedaanyang signifikan tentang penerapan metode SugestiImajinatif berbantuan gambar terhadap kemampuan menulis puisi pada siswa kelas III SDN Sukasari", ditolak.

Berdasarkan hasil pengujian hipotesis di atas, dapat diartikan bahwa antara vaiabel $X$ dan variabel $Y$ terdapat perbedaan yang signifikan. Dengan kata lain, kemampuan menulis puisi siswa dengan menggunakan metode Sugesti-Imajinatif berbatuan media gambar lebih baik dibandingkan dengan kemampuan menulis puisi siswa tanpa menggunakan metode Sugesti-Imajinatif berbantuan media gambar. Dalam hal ini, dapat disimpulkan bahwa penerapan metode SugestiImajinatif berbantuan media gambar berpengaruh terhadap peningkatan kemampuan menulis puisi siswa.

\section{E. Kesimpulan}

Berdasarkan penelitian dan hasil analisis data maka 
kesimpulan dari penelitian ini adalah sebagai berikut :

1. Pengaruh kemampuan menulis puisi siswa dengan menggunakan metode SugestiImajinatif berbantuan media gambar cukup baik dan meningkat. Hal itu dapat dilihat dari data mentah yang berupa puisi siswa dalam pembelajaran menulis puisi menggunakan metode Sugesti-Imajinatif berbantuan media gambar dengan pembelajaran menulis puisi sebelumnya. Pada pembelajaran menulis puisi dengan menggunakan metode Sugesti-Imajinatif berbatuan media gambar (Kelas Eksperimen), siswa sudah mampu memahami unsur-unsur intrinsik puisi sehingga kata-kata yang digunakan dalam puisi itu sudah cukup baik. Kesimpulan ini didukung dengan nilai distribusi pada pembelajaran menulis puisi, nilai rata-rata, dan persentase keberhasilan atau kemampuan kelas eksperimen dalam menulis puisi.

2. Pengaruh kemampuan menulis puisi siswa tanpa menggunakan metode Sugesti-Imajinatif berbantuan media gambar kurang baik. Hal ini dapat dilihat juga dari data mentah berupa puisi siswa dalam pembelajaran menulis puisi tanpa menggunakan metode SugestiImajinatif berbantuan media gambar. Siswa yang menulis puisi tanpa menggunakan metode Sugesti-Imajinatif berbantuan media gambar (Kelas Kontrol), masih belum memahami unsur-unsur intrinsik puisi sehingga kata-kata yang digunakan siswa kurang baik. Kesimpulan ini didukung dengan nilai distribusi pada pembelajaran menulis puisi, nilai rata-rata, dan persentase keberhasilan atau kemampuan kelas kontrol dalam menulis puisi.

3. Perbedaan pembelajaran menggunakan metode SugestiImajinatif berbantuan media gambar dalam kemampuan menulis puisi siswa dengan pembelajaran menulis puisi tanpa menggunakan metode Sugesti-Imajinatif berbantuan media gambar sangat terlihat 
Didaktik : Jurnal Pendidikan Guru Sekolah Dasar, ISSN : 24775673

Sekolah Tinggi Keguruan dan IImu Pendidikan Subang Volume IV Nomor 1, Juli 2018

dengan jelas. Puisi yang ditulis oles siswa di kelas Eksperimen (dengan perlakuan) lebih baik, tertatur dan terarah karena siswa sudah memahami dan mengerti bagaimana cara menulis puisi berdasarkan unsur-unsur intrinsik yang terdapat pada puisi dengan bantuan gambar. Imajinasi siswa lebih terangsang ketika mereka melihat gambar dan kemudian menuangkan ide/gagasan untuk menulis puisi. Sedangkan puisi yang ditulis oleh siswa di kelas Kontrol (tanpa perlakuan) kurang baik dan tidak teratur karena siswa kurang memahami dan mengerti bagaimana cara menulis puisi berdasarkan unsur-unsur intrinsik pada puisi. Hal itu berkaitan dengan pengujian hipotesis, nilai kelas Ekperimen (kelas $\mathrm{X}$ ) dan kelas Kontrol (kelas $\mathrm{Y}$ ) yang dianalisis secara statistik. Teknik analisis yang digunakan adalah teknik Test "t" untuk memperoleh nilai to (perbedaan dua mean). Dari hasil perhitungan tersebut, diketahui nilai to sebesar 4,36 .
Setelah dibandingkan dengan harga kritik " $t$ " atau nilai $t_{t}$ pada Tabel Nilai "t" dengan df sebesar 37 , ternyata nilai to jauh lebih besar daripada nilai $t_{t}$ sebesar 2,02 pada taraf signifikansi $5 \%$ atau taraf kepercayaan 95\% dan 2,71 pada taraf signifikansi $1 \%$ atau taraf kepercayaan 99\%. Karena nilai to lebih besar dari nilai $t_{t}$, maka hipotesis nihil (Ho) ditolak dan hipotesis alternatif/kerja (Ha), yakni "Terdapat perbedaanyang signifikan tentang penerapan metode Sugesti-Imajinatif berbantuan media gambar terhadap kemampuan menulis puisi siswa kelas III SDN Sukasari I", diterima.

\section{DAFTAR PUSTAKA}

Akhadiah. (1996). Menulis. Jakarta : Depdikbud.

AkhmadNamawi. "Peningkatan Kemampuan Menulis Puisi Melalui Metode SugestiImajinatif Dengan Media Lagu Siswa Kelas V SDN 2 Tanjung Alai".

Aminuddin. (2009). Pengantar Apresiasi karya Sastra. Bandung : Sinar Baru Algensindo. 
Depdikbud. (1994). Petunjuk Pengajaran Membaca dan Menulis di $S D$. Jakarta : Depdikbud.

Depdiknas. (2003). Kurikulum 2004 Standar Kompetensi Mata Pelajaran Bahasa Indonesia SD/MI. Jakarta : Depdiknas.

Hernilrmaniasari. "Pengaruh Metode Sugesti-Imajinasi Melalui Media Lagu Untuk Meningkatkan Kemampuan Menulis Karangan Deskripsi Siswa Kelas VIII SMP Negeri 3 Banyuresmi".

Isah Cahyani, Hodijah. (2007). Kemampuan Berbahasa Indonesia di Sekolah Dasar. Bandung : UPI PRES.

I Maryanti, Mukhidin, (2017) ,Penggunaan Media Audio, Untuk Meningkatkan Kemampuan Menyimak Cerita Rakyat Pada Mata Pelajaran Nahasa Indonesia kelas $V$ SD Negeri Lengkong, Jurnal PGSD Subang

Jalil, Abdul Daniel. (1990). Teori dan Priodisasi Puisi Indonesia. Bandung : Angkasa.

Mulyati, Yeti, dkk. (1998). Pendidikan Bahasa dan Sastra Indonesia di Kelas Tinggi. Jakarta : Depdikbud.

Mulyati, Yeti, dkk. (2007). Keterampilan Berbahasa Indonesia $S D$. Universitas Terbuka : Jakarta.

Moeliono, Anton, ed. (1990). Kamus Besar Bahasa Indonesia. Jakarta : Balai Pustaka.

Nurgyantoro, B. (2009). Penilaian dan Pengajaran Bahasa dan
Sastra Edisi Ketiga.

Yogyakarta: BPFE

Yogyakarta.

Pradopo, RachmatDjoko. (1997). Pengkajian Puisi : Analisis

Strata Norma dan Analisis Struktural dan Semiotik. Yogyakarta : Gajah Mada University Press.

Semi, M. Atar. (1990). Ancangan Pengajaran Bahasa dan Sastra Indonesia. Bandung : Angkasa.

Semi, M. Atar. (1995). Dasardasar Keterampilan Menulis. Bandung : Mugantara.

Situmorang, BP. Puisi dan Metodologi Pengajarannya.

Flores : Nusa Indah.

Sudijono, Anas.

(1992).

Pengantar Statistik

Pendidikan, Jakarta : CV. Rajawali.

Sudjana, Nana. (1992). Penilaian Hasil dan Proses Belajar Mengajar. Bandung Remaja Rosdakarya Offset.

Sugiyono, (2008). Metode Penelitian Pendidikan. Bandung : Alfabeta.

Sukardi, (2003). Metodologi Penelitian

PendidikanKompetensi dan Praktiknya. Jakarta : Bumi Aksara.

Sukmadinata, Nana Syaodih. (2005). Metode Penelitian Pendidikan. Bandung Rosda.

Sulvia Hidayat. dkk. (2010). Modul Pendidikan dan Latihan Guru Sekolah Dasar (SD) / Guru Kelas (Bahasa Indonesia, IPS, IPA, Matematika \&PKn). Bandung : Panitia Sertifikasi Guru Rayon 34 Universitas Pasundan. 
Sumiyadi. (1993). "Menilai dan Memilih Puisi Anak-anak". Baunga Rampai. Sastra dan Perkembangan Insani anakanak. Bandung : Mimbar Pendidikan Bahasa dan Seni, FSBS IKIP.

Tarigan, Djago. (1990). Materi Pokok Pendidikan Bahasa Indonesia 1. buku 1 : Modul 1-6. Jakarta : Depdikbud.

Tarigan, Djago. (1995). Membina Kemampuan Menulis Paragraf dan Pengembangannya. Bandung : Angkasa.

Tarigan, Djago. (1998). Buku Materi Pokok Kependidikan Keterampilan Berbahasa. Jakarta : Depdikbud.

TIM Bahasa Indonesia SD UPI. (2008). Pembelajaran Bahasa Indonesia SD. UPI Bandung.

Usman, Husnaini dan PurnomoSetiady Akbar. (2003) Pengantar Statistik. Jakarta: PT Bumi Aksara.

Zainurrahman. (2013). Menulis : Dari Teori Hingga Praktik (Penawar Racun Plagiarisme). Bandung : Alfabeta.

Zuchdi, D. dkk. (1997). Pendidikan Bahasa Indonesia di Kelas Rendah. Jakarta : Depdikbud. 